\title{
Foreign Direct Investment in China, the Factors Determining a Preference for Investing in Eastern or Western Provinces
}

\author{
Alex Granneman, Meine Pieter van Dijk* \\ The Erasmus University, Rotterdam, Netherlands \\ Email:
}

Received 15 July 2015; accepted 24 August 2015; published 27 August 2015

Copyright (C) 2015 by authors and Scientific Research Publishing Inc.

This work is licensed under the Creative Commons Attribution International License (CC BY). http://creativecommons.org/licenses/by/4.0/

(c) (i) Open Access

\section{Abstract}

Why do foreign enterprises invest in certain provinces of China? This study started with five possible factors that could influence the decision of multinational corporations: 1) Economic growth; 2) Labor costs; 3) Domestic investments; 4) Agglomeration advantages; and 5) Innovation. The Eastern and Western provinces are slowly converging in terms of foreign direct investments (FDI) and growth rates. Especially after the 11th and 12th five year plans, which were primarily aimed at opening up the Western part of China. Based on a data for the time period 1992-2012 for each of the 30 provinces we analyzed the hypotheses derived from Dunning [1]. After checking for normality and multi-collinearity we estimated the coefficients of the independent variables and their statistical significance. To find different determinants across China, this study opted to do the analysis for the Eastern and Western provinces of China separately. GDP Growth is found to be positively related to FDI in both cases. The wage level is only found to be significant in the Eastern provinces. A reason for this can be that the Eastern China is a step ahead of the Western China, higher educated people are needed and hence higher labor costs are accepted. Domestic investments are found to have a positive effect on FDI in both models. Finally the indicator for agglomeration has a positive significant coefficient: already existing businesses pull MNEs. This effect is found to be stronger in the Eastern provinces; this can be due to the fact that more MNEs have already established their businesses over there. Lastly, the variable patent has the wrong coefficient in both models. These results have policy implications and confirm the importance of certain location factors as suggested in the Dunning model. The government can stimulate FDI in the western provinces by promoting domestic investments in these provinces. Also agglomeration attracts FDI and can be promoted.

\footnotetext{
${ }^{*}$ Corresponding author.
} 


\section{Keywords}

\section{Investment, Labor Cost, Agglomeration, Innovation, FDI (Foreign Direct Investment), Domestic Investment, Regional Inequality}

\section{Introduction}

China became an attractive location for Foreign Direct Investment (FDI) after the economic reform and opening up policies in 1979. The transition from a planned economy towards a more market oriented system resulted in a slowly globalizing economy. Initially, Chinese reformers were somewhat skeptical about the open market and therefore they placed many restrictions on FDI. Multi-National Enterprises (MNEs) were only allowed to locate and invest in Special Economic Zones (SEZs), which were located in the southern provinces of Guangdong and Fujian. As a result of this, the coastal provinces are now much better off than the inland provinces. In this article, we analyzed the consequences of this unequal FDI development and provided suggestions how China could stimulate more FDI going towards the inland provinces. We started to analyze the trend of FDI in China, and then compared the Eastern and Western provinces. By using data from 1992 until 2012 we would identify variables that influenced the amount of FDI per province. We would argue that the Eastern and Western provinces were converging in terms of share of FDI and growth of regional GDP, but that large differences still existed and that a limited number of variables influenced the current trends.

\section{FDI Development in China}

After the opening up of China, FDI flows started to increase into China. Initially FDI inflows grew slowly, because only the Guangdong and Fujian province were open to the international capital in the years immediately after the reforms. As years passed, more cities and economic zones were established, which resulted in a strong increase in FDI. Important years that FDI increased to higher levels are 1992 and 2001. In 1992, the former president Deng Xiaoping went on his famous Southern tour. His speech reassured foreign investors. China would continue to liberalize its economy. They regained trust in China's economic development. A sharp increase in FDI in the year after this trip was the result. In 2001, China was admitted to the World Trade Organization (WTO). The requirements of the WTO included removal of trade barriers, reduction of foreign ownership limitation in some sectors, no more location restrictions and equal chances for domestic and international banks. This resulted in substantial increases in FDI. A visual summary can be found in Figure 1. A steady increase in FDI looks promising, but if we look at the provincial level we see vast differences between the Eastern and Western provinces of China.

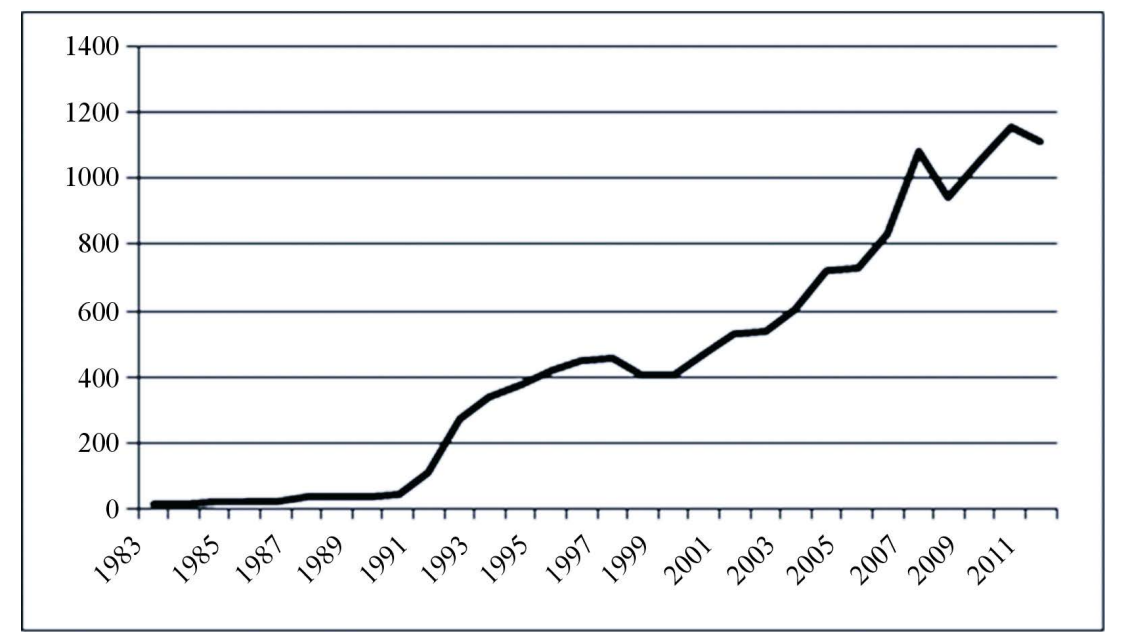

Figure 1. FDI inflows from 1983-2012 (in 100 million USD). Source: Compiled by the authors, Chinese statistical yearbooks and Ministry of Commerce (2012). 


\section{FDI Distribution across China}

More than $90 \%$ of the FDI went to Eastern provinces (or less than $10 \%$ to Western provinces) in the beginning of the 1990s Table 1. The Chinese government realized that FDI and economic growth go hand in hand, but disparity levels between East and West became larger and larger. This resulted in several policies to attract more FDI to Western China. The trend is visualized in Figure 2, showing increasing FDI in the Western provinces, but still important differences exist. We note that around 70\% of FDI was located in Eastern provinces (consequently 30\% in Western provinces) in 2012.

We use data at the provincial level. It is interesting to see how the share of inward FDI changes over time per province. The exact share of FDI per provinces for the years 1992, 2002 and 2012 is shown in Table 2. The general picture is that most of the FDI inflow went to the coastal areas (about 92\%). A large amount of FDI went into the southern provinces of Guangdong and Fujian in the 1990s. These provinces were the first ones to have SEZs and therefore attracted more FDI compared to other provinces. Ten years later, in 2002, the numbers are slightly different, but most of the FDI is still going to the coastal areas (about 88\%). FDI inflows are increasing in provinces like Jiangsu, Zhejiang and Shanghai where new SEZ were opened. Lastly, the distribution of FDI in 2012 shows that highest shares of FDI are still to be found in the eastern part of China (Guangdong, Jiangsu and Liaoning). However, it can be noted that FDI is slowly distributed more equally across the country. This means that the policies to promote investment in Western China, formulated in the 11th and 12th five year plans, are paying off.

\section{Origins of FDI}

Having shown in which regions FDI is concentrated, it is interesting to see what the origins of these investments are. For the year 2012, the distribution is visualized in Figure 3. One observes that a large share of the FDI comes from Asian countries, which indicates that proximity to markets is important for investors. Furthermore, Latin America and Europe also represent a significant share of Chinese inward FDI (9.1\% and 5.6\% respectively). The other continents, North America, Oceania and Africa, only represent a small share (less than 3 percent).

When looking at individual countries, some countries stand out. The largest investor, in terms of FDI, is Hong Kong. Hong Kong is situated in close proximity to China and represents 54\% of China's inward FDI in 2012. Other Asian countries with relatively large shares are Japan, Singapore and South Korea. Showing shares of $6.1 \%, 5.2 \%$ and $2.5 \%$ respectively. The United States represent a share of $2.1 \%$ of total FDI. Of the European etc. countries, Germany and the Netherlands are the largest investors. $1.2 \%$ and $0.9 \%$ respectively. Lastly, there are two countries that are initially surprising because of their size. These are the Cayman and Virgin Islands, representing shares of $1.6 \%$ and $6.5 \%$ respectively ${ }^{1}$. Important to notice is that Hong Kong, the Cayman Islands and the Virgin Islands are well known places to store money, also known as investments hubs. This means that the actual investments may come from other countries, including mainland China, but this is not easily traceable.

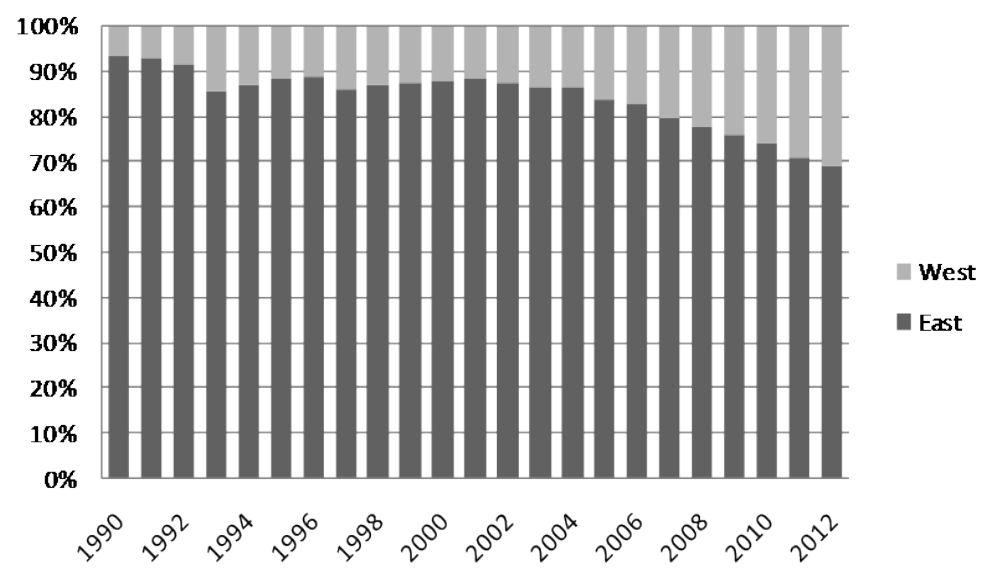

Figure 2. Share of inward Foreign Direct Investments. Source: Compiled by the authors, China Statistical Yearbooks, different years.

\footnotetext{
${ }^{1}$ Numbers have been calculated by using data from the website of the Ministry of Commerce (2012).
} 


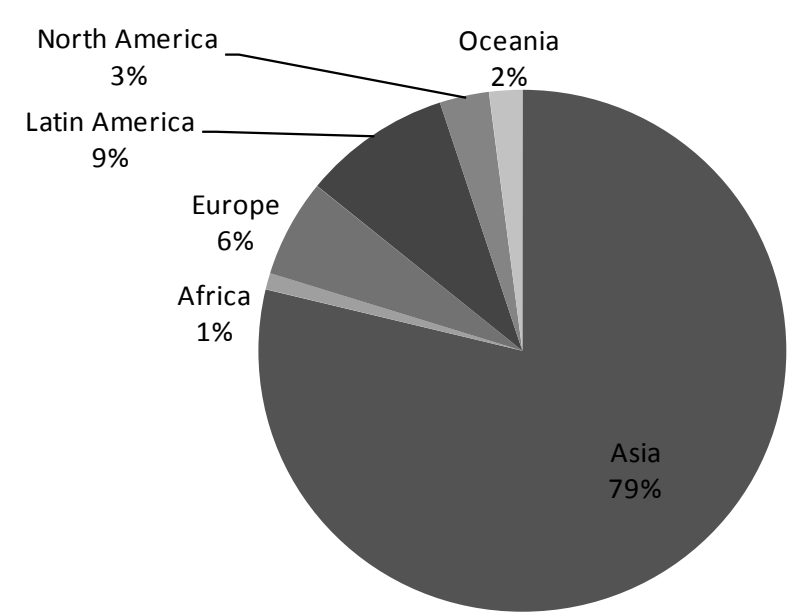

Figure 3. Origins of China's inward FDI (2012). Source:

Compiled by the authors, Ministry of Commerce.

\section{Table 1. Division of China's provinces.}

\begin{tabular}{cc}
\hline Eastern Provinces & Western Provinces \\
\hline Beijing & Anhui \\
Fujian & Chongqing and Sichuan (Combined) \\
Guangdong & Gansu \\
Hainan & Guangxi \\
Hebei & Guizhou \\
Heilongjiang & Henan \\
Jiangsu & Hubei \\
Jilin & Hunan \\
Liaoning & Inner Mongolia \\
Shandong & Jiangxi \\
Shanghai & Ningxia \\
Tianjin & Qinghai \\
Zhejiang & Shaanxi \\
& Shanxi \\
& Tibet \\
& Xinjiang \\
& Yunnan \\
& \\
\hline
\end{tabular}

Source: Compiled by the authors.

\section{Underlying Theory}

The interest in the topic of FDI and consequently the development of theoretical models that could explain the occurrence of FDI flows began in the 1960s, just when FDI flows started to arise [2] [3]. At that time, however, there was no underlying theoretical model and FDI was explained on the basis of trade theories. As times passed, multiple researchers have attempted to develop a comprehensive theoretical model for FDI. Most researchers built their models on one of the following theories: international trade theory [4], product life cycle theory (Vernon, 1966 [5]), the division of FDI [6], the oligopolistics reaction hypothesis [7], market imperfection theory [8], the internalizing theory [9], or the eclectic theory [10]. Dunning’s eclectic paradigm will be used as 
Table 2. FDI shares per province (percentage of total).

\begin{tabular}{|c|c|c|c|}
\hline & 1992 & 2002 & 2012 \\
\hline \multicolumn{4}{|l|}{ Eastern Provinces } \\
\hline Beijing & 8.15 & 3.29 & 3.34 \\
\hline Fujian & 12.22 & 7.32 & 2.63 \\
\hline Guangdong & 31.77 & 21.60 & 9.77 \\
\hline Hainan & 3.88 & 0.98 & 0.68 \\
\hline Hebei & 0.97 & 1.49 & 2.41 \\
\hline Heilongjiang & 0.62 & 0.68 & 0.79 \\
\hline Jiangsu & 12.56 & 19.42 & 14.84 \\
\hline Jilin & 0.65 & 0.47 & 0.68 \\
\hline Liaoning & 4.43 & 6.50 & 11.11 \\
\hline Shandong & 8.61 & 9.02 & 5.12 \\
\hline Shanghai & 4.24 & 8.14 & 6.30 \\
\hline Tianjin & 0.93 & 3.01 & 6.23 \\
\hline Zhejiang & 2.52 & 5.86 & 5.42 \\
\hline \multicolumn{4}{|l|}{ Western Provinces } \\
\hline Anhui & 0.43 & 0.73 & 3.58 \\
\hline Chongqing & N/A & 0.37 & 4.37 \\
\hline Gansu & 0.00 & 0.12 & 0.03 \\
\hline Guangxi & 1.56 & 0.80 & 0.31 \\
\hline Guizhou & 0.17 & 0.07 & 0.43 \\
\hline Henan & 0.46 & 0.77 & 5.03 \\
\hline Hubei & 1.74 & 2.72 & 2.35 \\
\hline Hunan & 1.14 & 1.72 & 3.02 \\
\hline Inner Mongolia & 0.04 & 0.34 & 1.64 \\
\hline Jiangxi & 0.83 & 2.06 & 2.83 \\
\hline Ningxia & 0.00 & 0.04 & 0.14 \\
\hline Qinghai & 0.01 & 0.09 & 0.09 \\
\hline Shaanxi & 0.39 & 0.69 & 1.22 \\
\hline Shanxi & 0.46 & 0.40 & 0.43 \\
\hline Sichuan & 0.96 & 1.06 & 4.09 \\
\hline Tibet & 0.00 & 0.00 & 0.04 \\
\hline Xinjiang & 0.00 & 0.04 & 0.17 \\
\hline Yunnan & 0.25 & 0.21 & 0.91 \\
\hline
\end{tabular}

Source: compiled by the authors and various Yearbooks of the CSP (2013) [21].

the underlying theory for this paper, since it is the most comprehensive theory which has also been used by other researchers [11].

Dunning [10] suggests that the drive for a firm to engage in FDI is determined by three conditions that are available to the investing firm compared to host country firms [4]. These conditions are 1) Ownership advantages; 2) Location advantage; and 3) Internalization advantages. Also known as the OLI tripod. 


\subsection{Ownership Advantages}

This part of the tripod relates to firm specific ownership advantages discussed in Hymer's market imperfection theory [8]. These firm-specific advantages arise when a MNE possesses intangible assets that are not available to other firms. Examples of these intangible assets are technology, brand, and scale economies. These core competencies are necessary, because a MNE may have additional costs (e.g. cultural, language, legal differences, failure of the local market and costs of operating from a distance) and these need to be offset by higher revenues or lower costs generated by these firm specific advantages. According to Dunning [12], the theory developed by Hymer was on the right track, but understanding of the importance of the local market environment was missing.

\subsection{Location Advantages}

The second complementary part of the tripod relates to location specific advantages. This implies that a MNE needs to gain benefits from locating in a certain country, otherwise there would not be an incentive to engage in FDI. MNE may have to be located close to particular resources or in proximity of customers to minimize transaction costs. This part of the paradigm had been extended by Dunning in 1993 [13], when he stated that MNEs have different motives when investing in a foreign market. These motives are: market seeking (e.g. transferring investments abroad to protect or gain market share, especially in case of fast growing industries), resource seeking (e.g. move operations towards resource abundant countries, which results in cost reductions and thus make the MNE more competitive), efficiency seeking (e.g. reduce costs and increase efficiency by operating with different endowment factors) and strategic-asset-seeking (e.g. protect ownership and increase comparative advantages) [1] [13].

\subsection{Internalization Advantages}

The last part of Dunning's tripod has to do with the protection of firm-specific ownership advantages. It would be best for a MNE to beneficially exploit these advantages, instead of selling or leasing the right to foreign firms [14]. Dicken [16] states that the more imperfect a market is, the more incentives there are for the MNE to internalize market transactions and perform those parts of the supply chain by itself. In the end the net benefit of internalizing market transactions should always outweigh the benefits of licensing to another firm [1].

The combination of various theories into one paradigm made this eclectic theory of Dunning the most popular and comprehensive theory in the field of FDI. However, it is difficult to empirically test this theory in its existing form. Empirical work that used the eclectic paradigm as an underlying theory usually looked to one or several components of the theory [10]. In this line, the present study will conduct an empirical test focusing on the assumed location advantages in Dunning's theory [1] [10].

\section{Methodology}

We analyzed longitudinal data, available for all China's provinces. The main goal is to test the hypotheses formulated in the theoretical section. The model that will be estimated will be applied for the Eastern provinces (Model 1) and for the Western provinces (Model 2). This could indicate different determinants for investment across China.

We used secondary data to test the validity hypotheses stated in the theoretical section. These secondary data came from CEIC China Premium Database (www.ceicdata.com) and the Chinese statistical yearbooks (19922012; CSP, 2013) [21]. This study will primarily look at the database and will only make use of the statistical yearbooks whenever data is missing or seems not to be right. Quantitative data is collected for each of the provinces for the years 1992-2012. This timeframe captures several important events that influence the inflow of FDI: the Asian economic crisis (1997), the admittance to the WTO (2001) and the world financial crisis (2007).

Data for 30 provinces of the People's Republic of China were used. Chongqing is combined with Sichuan province, the province where Chongqing was part of before it became a separate city state with provincial status in 1996. All the provinces are listed in Table 1 and are divided in Western and Eastern provinces by using China's standard classification. This will allow us to find out whether the policies of opening up the west are paying off or not. Although, vast differences exist within provinces, using provincial level data allows us to discover patterns between groups of provinces, in particular the Eastern and Western provinces. 
The regression model used in this study consists of one dependent variable and several independent variables. The variables have been selected based on the theoretical framework, the availability of data and previously conducted research. The model is visualized in Table 3. The dependent variable in our model is Foreign Direct investment and will be measured by the actual amount of utilized FDI for each of the provinces. These numbers are generally published in US dollars and have been converted to RMB by using the real exchange rates for the respective years. Besides the dependent variable this model includes five independent variables. Many other variables, including social variables, could have been included, but based on the literature used to formulate our hypotheses, we will only make use of the following five variables. First of all, the variable Economic growth is considered a robust determinant of FDI. Commonly measured by annual (GDP-Growth). The second possible determinant of FDI is labor costs. This determinant will be measured by the average annual wage (WAGE), which is published in RMBs. The third determinant is Domestic Investment. This will be measured by the amount of Fixed Asset Investments (DINV). The fourth determinant is Agglomeration (AGGLO). In order to measure this factor, we use the total number of Foreign Funded Enterprises in a certain province. Lastly, we include a variable for innovation. This variable is measured by the number of patents granted (Patents), reflecting the innovative environment in a province.

One of the assumptions for the regression model is that the variables are normally distributed. This is in particular necessary when conducting a longitudinal analysis. When a variable does not show a normal distribution, one could transform the variable by taking the natural logarithm, which results in a distribution close to the normal distribution, but at the same time one should keep in mind that the this transformation will also transform the expected non-linear relation to a linear one. This will also affect the interpretation of estimated coefficients later on in this study. One can now interpret the coefficients as elasticities. In other words a one percentage change in the independent variable will result in a certain percentage change in the dependent variable. Whether a variable is normally distributed or not can be concluded from a Skewness and Kurtosis test ${ }^{2}$. The values of this test will be presented with the descriptive statistics in the empirical section of this study. Second, one can visually observe a normal distribution when looking at histograms. The complete set of variables used is summarized in Table 3.

There are three different ways to analyze longitudinal data. These are the Pooled Ordinary Least Squares (OLS) model, the Fixed Effect model (FE model) and the Random Effect model (RE model). An OLS model is used to analyze cross-sectional data only. Therefore, this study will not use the OLS model, because the OLS model does not take into account the time dimension of the data set. The two models left to be used are the FE and RE model, which both originate from the OLS model. Both models do, however, include a time dimension and are therefore suitable for this study. The main difference between the FE and RE model lies in the unobserved heterogeneity at the unit level $\left(u_{i}\right)$, also known as the disturbance term. The FE model controls for this unit's specific

Table 3. Summary of variables used in our models.

\begin{tabular}{cccc}
\hline Determinants & Variable & Acronym & Units \\
\hline $\begin{array}{c}\text { Dependent Variable } \\
\text { Foreign Direct Investments } \\
\text { Independent Variables }\end{array}$ & Actual Utilized FDI & LnFDI & RMB \\
Economic Growth & Indices \\
Labour Cost & Average Annual Wage & GDP Growth & RMB \\
Domestic Investments & Fixed Asset Investments & LnDINV & RMB \\
Agglomeration & Number of Foreign Funded Enterprises & LnAGGLO & Absolute Number \\
Innovation & Number of Patents Granted & LnPatents & Absolute Number \\
\hline
\end{tabular}

${ }^{2}$ The Skewness and Kurtosis test consists of two tests. On the one hand, Skewness indicates whether a distribution is skewed and if this is the case is it left or right skewed. Kurtosis on the other hand measures the thickness of the tails. Values between -1 and +1 for Skewness and a value close to 3 suggest a normal distribution of the variable (Corrado and Su, 1996) [15]. 
heterogeneity through the elimination of all time variant characteristics of each unit [17]. The RE model on the other hand assumes that the unobserved heterogeneity is random and uncorrelated with the other variables in the analysis. A test that could be used in order to make a decision between the models is the Hausman Test. This test looks for any correlation between the unit specific unobserved heterogeneity and all the other variables in the model. If the Hausman test rejects the null hypothesis $\left(\mathrm{H}_{0}\right.$ : the $\mathrm{RE}$ estimation model is the most suitable to analyze the data), then the FE model is recommended to be chosen over the RE model [17]. Clark and Linzer [18], however, state the Hausman test is neither a necessary nor a sufficient statistic to decide between the two models. This study opts to use the Hausman test as an indicator for using either the FE or the RE model. The general model is formulated as follows:

$$
\operatorname{LnFDI}_{i t}=\beta_{0}+\beta_{1} \text { GDPGrowth }_{i t}+\beta_{2} \text { LnWAGE }_{i t}+\beta_{3} \operatorname{LnDINV}_{i t}+\beta_{4} \operatorname{LnAGGLO}_{i t}+\beta_{5} \text { LnPatents }_{i t}+e_{i t}
$$

All statistical tests were carried out by using the statistical program STATA 12.

\section{Results}

\subsection{Model 1: Eastern Provinces}

A descriptive summary of the statistics used to analyze Model 1 is presented in Table 4, providing the number of observations, the mean, standard deviation, the minimum and maximum values and the results of the two tests for normality.

To test for multicollinearity, we only use the variables that show a correlation smaller than 0.9. Furthermore, we make use of the VIF approach to test for multicollinearity as well. The limit set here is a VIF value of 7.5. Our model contains the following independent variables 1) GDP Growth; 2) LnWAGE; 3) LnDINV; 4) LnAGGLO; and 5) LnPatents, the variable with the highest Variance Inflation Factor in this model is LnDINV (VIF = 4.74) $)^{3}$. To test whether the Fixed Effect model of the Random Effect model should be used, a Hausman test is carried out.

\begin{tabular}{cc}
\hline \multicolumn{2}{c}{ Hausman Test } \\
\hline $\mathrm{X}^{2}(5)$ & 13.45 \\
Prob $>$ Chi-squared & 0.0195 \\
\hline
\end{tabular}

The Hausman test results in a $p$-value of 0.0195 , which is significant and therefore the Fixed Effect model is used. The Fixed Effect model estimation is presented in Table 5.

The empirical results show an R-square value of 0.8548 . This indicates that the independent variables explain a large share (85 percent) of the variance of the dependent variable LnFDI. The Fixed Effect model estimates

Table 4. Descriptive summary of statistics for Model 1.

\begin{tabular}{cccccccc}
\hline Variable & Obs & Mean & Std. Dev. & Min & Max & Skewness & Kurtosis \\
\hline LnFDI & 273 & 23.66005 & 1.298623 & 19.80193 & 26.14263 & -0.3680819 & 2.597378 \\
GDP Growth & 273 & 112.3723 & 3.55225 & 104.3 & 140.2 & 0.9622622 & 4.874924 \\
LnWAGE & 273 & 9.510376 & 0.8539339 & 7.738488 & 11.34737 & -0.0557264 & 2.126395 \\
LnDINV & 273 & 26.04775 & 1.265095 & 23.14185 & 28.77065 & -0.0092073 & 2.328748 \\
LnAGGLO & 273 & 9.330647 & 0.9668721 & 6.785588 & 11.49846 & -0.0187914 & 2.379653 \\
LnPatents & 273 & 5.746807 & 1.887576 & 0 & 10.00573 & 0.0717638 & 2.677475 \\
\hline
\end{tabular}

Source: analysis by the authors.

${ }^{3}$ The Variance Inflation Factor (VIF) is a widely used measure of the degree of multicollinearity of an independent variable with another independent variable. It is measured as the reciprocal of tolerance, where tolerance is measure as 1 minus the proportion of variance share with other independent variables. Multicollinearity can be reduced by eliminating the variables with VIF variables higher than the set threshold (O’Brien, 2007) [19]. 
Table 5. Regression results for Model 1 using Fixed Effects.

\begin{tabular}{cc}
\hline GDP Growth & Fixed Effect Model \\
\hline LnWAGE & $0.0186402^{*}$ \\
& $(2.45)$ \\
LnDINV & $0.5232329^{* * *}$ \\
& $(4.59)$ \\
LnAGGLO & $0.4290154^{* * *}$ \\
& $(5.49)$ \\
LnPatents & $0.744678^{* * *}$ \\
& $(11.89)$ \\
(Constant) & $-0.269614^{* * *}$ \\
& $(-8.73)$ \\
Observations & 0.0133659 \\
F statistic of the model & $(0.01)$ \\
Adjusted R-square & 272 \\
\hline
\end{tabular}

Note: $t$ statistic in parentheses. $(*)$ significant at $5 \%$ level; $(* *)$ significant at $1 \%$ level; $\left({ }^{* * *}\right)$ significant at $0.1 \%$ level.

that there is a strong positive and highly significant ( $p$-value $<0.001$ ) relation between LnFDI and the variables LnWAGE, LnDINV and LnAGGLO. To be precise, a $1 \%$ increase in these variables leads to an increase in LnFDI of $0.52 \%, 0.43 \%$ and $0.74 \%$ respectively. The positive relation between LnWAGE and LnFDI could indicate the need for educated labor and consequently higher labor costs in the Eastern provinces. The positive relation between LnDINV and LnFDI is in line with the suggestion that domestic investments stimulate FDI. LnAGGLO, on the other is suggested to create an attractive environment for future FDI. Furthermore, a positive weakly significant $(p$-value $<0.05$ ) relation is found between the variable GDP Growth and LnFDI. In this case, a $1 \%$ increase in GDP Growth results in a $0.02 \%$ increase in LnFDI. This indicates that a growing economy attracts FDI. Lastly, a negative and highly significant relation is found between the variable LnPatents and LnFDI. A $1 \%$ increase in LnPatents leads to a decrease of the variable LnFDI by $0.27 \%$. This is an interesting result, because at first sight one would think that patents could stimulate FDI, because it suggests an innovative environment with possible spillovers effects. The negative estimated relation may reflect the fact that the Chinese are known as notorious copy cats and this could scare off potential foreign investors (Chu, 2012 "Chinese copycats challenge US small businesses").

\subsection{Model 2: Western Provinces}

A descriptive summary of the statistics used to analyze Model 2 is presented in Table 6 indicating the number of observations, the mean, standard deviation, the minimum and maximum values and the results of the two tests for normality.

Again we will only use variables that show a correlation smaller than 0.9. Furthermore, we also make use of the VIF approach to test for multicollinearity,while the limit is set at 7.5. Our model contains the following independent variables 1) GDP Growth; 2) LnWAGE; 3) LnDINV; 4) LnAGGLO; and 5) LnPatents. The variable with the highest VIF in this model is LnDINV (VIF $=7.10$ ). The mentioned variables are not likely to show multicollinearity, because all the variables show a VIF $<7.5$. To test whether the Fixed Effect model of the Random Effect model should be used, a Hausman test is carried out. 


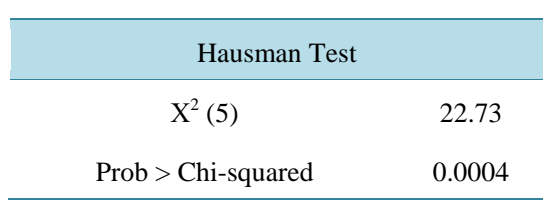

Table 6. Descriptive summary of statistics for Model 2.

\begin{tabular}{cccccccc}
\hline Variable & Obs & Mean & Std. Dev. & Min & Max & Skewness & Kurtosis \\
\hline LnFDI & 341 & 21.42425 & 1.895273 & 14.47309 & 25.58148 & -0.5671494 & 3.603243 \\
GDP Growth & 357 & 111.6287 & 2.696917 & 105.1 & 123.8 & 0.6922906 & 4.316716 \\
LnWAGE & 357 & 9.317197 & 0.8273184 & 7.675082 & 10.85331 & -0.0046689 & 1.9495 \\
LnDINV & 357 & 25.22653 & 1.508687 & 21.10375 & 28.57789 & -0.0484076 & 2.602342 \\
LnAGGLO & 357 & 7.223798 & 1.320268 & 1.791759 & 9.733707 & -0.916233 & 3.827926 \\
LnPatents & 348 & 4.494457 & 1.734542 & 0 & 8.837246 & -0.0092688 & 2.727277 \\
\hline
\end{tabular}

Source: analysis by the authors.

The Hausman test results in a p value of 0.0004 , which is significant and therefore the Fixed Effect model is used. The Fixed Effect model estimation is presented in Table 7.

The empirical results show an R-square value of 0.7357 . This indicates that the independent variables explain a large share (74 percent) of the variance of the dependent variable LnFDI. The Fixed Effect model estimates that there is a strong positive and highly significant $(p$-value $<0.001)$ relation between LnFDI and the variable LnAGGLO. To be precise, a $1 \%$ increase in LnAGGLO leads to an increase in LnFDI of $0.41 \%$. Similar explanation as for the Eastern provinces, agglomeration could create a favorable environment for future FDI. Furthermore, a positive significant ( $p$-value $<0.01$ ) relation is found between the variable LnDINV and LnFDI. In this case, a $1 \%$ increase in LnDINV results in a $0.70 \%$ increase in LnFDI. This suggests that domestic investment in the western provinces would have the largest effect on LnFDI. A positive weakly significant ( $p$-value < 0.05 ) is estimated for the variable GDP Growth and LnFDI. A 1\% increase in GDP Growth results in a 0.04\% increase in LnFDI. An insignificant result is found for the variable LnWAGE, therefore no further conclusions can be drawn for this variable. Lastly, a negative and highly significant relation is found between the variable LnPatents and LnFDI. A $1 \%$ increase in LnPatents leads to a decrease of the variable LnFDI by $0.27 \%$. A similar explanation as given for the wrong negative sign for this variable in Model 1 could explain this relation.

Comparing both models

In order to find out whether there are different location factors of FDI across China, this section will compare the two models. The estimated coefficients and significance levels for each of the models are summarized in Table 8.

The estimations provide interesting results given this set of variables. The first variable to be discussed is GDP Growth. The variable GDP Growth is found to be positively related to LnFDI in both models and is an indication of the importance of the size of the market. A weakly significant coefficient was estimated in both models. However, seems to be larger in the Western Model, meaning that growth in the Western provinces will result in relatively more FDI than growth in the Eastern provinces, showing again the importance of market size (similar population but much higher income). The variable LnWAGE is only found to be a significant variable in the Eastern provinces. A reason for this could be that, because Eastern China is a step ahead of Western China, higher educated people are needed and hence investors know they have to pay higher wages. The third variable, LnDINV, is found to have a positive effect on LnFDI in both models. The effect itself is estimated to be larger in the Western Provinces. LnAGGLO is also estimated with a positive significant coefficient meaning that already existing businesses create a pull effect for MNEs. This effect is found to be stronger in the Eastern provinces, this could be due to the fact that more MNEs have already established their businesses over there. Lastly, the variable LnPatents, is estimated with a negative coefficient in both models. The effect is similar in the East and in the West, suggesting that this variable has a similar effect on LnFDI across China, or the notorious copycatting is still influencing the decision of MNEs to invest in China negatively. 
Table 7. Regression results for Model 2 using Fixed Effects.

\begin{tabular}{cc}
\hline GDP Growth & Fixed Effect Model \\
\hline LnWAGE & $0.0354196^{*}$ \\
& $(2.19)$ \\
LnDINV & 0.428594 \\
& $(1.26)$ \\
LnAGGLO & $0.7016422^{* *}$ \\
& $(2.79)$ \\
LnPatents & $0.4056939 * * *$ \\
& $(4.96)$ \\
(Constant) & $-0.2728365^{* * *}$ \\
& $(-3.42)$ \\
Observations & -6.030654 \\
F statistic of the model & $(-1.92)$ \\
Adjusted R-square & 339 \\
\hline
\end{tabular}

Note: $t$ statistic in parentheses. $\left({ }^{*}\right)$ significant at $5 \%$ level; $(* *)$ significant at $1 \%$ level; $\left({ }^{* * *}\right)$ significant at $0.1 \%$ level.

Table 8. Summary of the final regression results of the two models.

\begin{tabular}{ccc}
\hline & Eastern Model & Western Model \\
\hline GDP Growth & $0.0186402^{*}$ & $0.0354196^{*}$ \\
LnWAGE & $(2.45)$ & $(2.19)$ \\
LnDINV & $0.5232329^{* * *}$ & 0.428594 \\
& $(4.59)$ & $(1.26)$ \\
LnAGGLO & $0.4290154^{* * *}$ & $0.7016422^{* *}$ \\
& $(5.49)$ & $(2.79)$ \\
LnPatents & $0.744678^{* * *}$ & $0.4056939^{* * *}$ \\
& $(11.89)$ & $(4.96)$ \\
(Constant) & $-0.269614^{* * *}$ & $-0.2728365^{* * *}$ \\
& $(-8.73)$ & $(-3.42)$ \\
F statistic of the model & 0.0133659 & -6.030654 \\
Adjusted R-square & $(0.01)$ & $(-1.92)$ \\
\hline
\end{tabular}

Note: $t$ statistic in parentheses. $(*)$ significant at $5 \%$ level; $(* *)$ significant at $1 \%$ level; $(* * *)$ significant at $0.1 \%$ level. 


\section{Conclusions}

Since the economic reform that started in 1979, China gradually opened up its borders to the international market. From that moment on, China's economy started to grow slowly and at the same time FDI started to rise. Several laws that were adopted, political developments and the admission to the WTO gave extra impulses to the increase in FDI. At the same time, China started to become more and more unequal, which was very worrisome for the Chinese government. Most of the foreign investments were initially guided into so called Special Economic Zones, which were located along the East coast of China. Many researchers provided evidence for the positive relation between FDI and economic growth, because investors were constantly seeking new markets. In line with this, the highest growth rates were established in the Eastern provinces.

Is it possible for the government to stimulate FDI in the western provinces in order to reduce inequality? Which policies should the Chinese government implement to make this happen? This is the starting point of the current study. By investigating how certain location variables affect FDI, one can come up with some policy recommendations. The effects of variables like domestic investment and agglomeration were larger for the Western regions. A goal for policy makers can be to further stimulate economic growth in Western provinces (one can think of increasing domestic investments). Against the expectations, the variable LnWAGE was estimated positively as well, with a stronger effect in Western provinces. As discussed in the research section, it can indicate that this is because of the search for skilled labor. In this sense, the variable LnWAGE captures more the skill level of the worker rather than the cost of labor. This is in line with Sun et al. [11]. A second goal for policy makers is to stimulate wage increases in Western provinces. This was already partly done by the action plan for education development in 1999, which resulted in higher educated labour that was asking higher wages. The positive coefficient of the variable LnDINV is in line with Van Dijk [20] who finds that FDI comes after domestic investments have taken place. It shows that domestic investments done in the Western provinces will stimulate the flow of FDI towards the Western provinces greatly. In line with Dunning's theory, the variable LnAGGLO is also found to be positively related to FDI. Indicating that creating a favorable environment for MNEs can stimulate more FDI through the pull effect of MNEs already established in China. This can be a third goal for policy purposes. It is however the question until what extent the Chinese government wants to help MNEs, because the government also wants to protect and stimulate the domestic investors. The effect seems larger for the Eastern provinces, but this can be due to that fact that more MNEs are located there. Lastly, the variable LnPatents is estimated with a negative coefficient in both models. This can indicate that the lack of value in patents is scaring away potential MNEs.

A limitation of the current study is that it is primarily focused on the provincial level. As MNEs investing in cities rather than in the whole province, one should be careful while interpreting these results for smaller cities or towns. It is mainly due to the unavailability of data at the city level that a provincial level study is opted. However, the authors think that the results still provide a good insight in certain location determinants and trends in China.

Another limitation is that this study looks at all industries combined, but it could be that certain findings are only valid in certain industries. For example, a finding can be valid in the electronic industry and not in the manufacturing industry [22].

For future research we recommend conducting a similar approach, but at a less aggregated level. This could be at the prefecture level, but also at the county level. At the same time one should take into account that certain variables used in this study may not be available at those levels. Working with, and obtaining consistent Chinese data can be a problem. Taking into account that China is commonly divided in urban and in a rural areas, it would be interesting to see whether the results obtained in this study are mainly derived from the urban areas, or that rural areas also have an impact on the outcome.

\section{References}

[1] Dunning, J.H. (2000) The Eclectic Paradigm as an Envelope for Economic and Business Theories of MNE Activity. International Business Review, 9, 163-190. http://dx.doi.org/10.1016/S0969-5931(99)00035-9

[2] Jones, J. and Wren, C. (2006) Foreign Direct Investment and the Regional Economy. Ashgate publishing, Farnham.

[3] Almahmood, A. (2010) Foreign Direct Investment in Saudi Arabia: Joint Venture Equity Shares and Source Country Characterisitcs. Thesis, Newcastle University, Newcastle.

[4] Dunning, J.H. (1977) Trade, Location of Economic Activity and the MNE: A Search for an Eclectic Approach. In: Oh- 
lin, B., Hesselborn, P.O. and Wijkman, P.M., Eds., The International Allocation of Economic Activity, MacMillan, London, 395-418.

[5] Vernon, R. (1966) International Investmeent and Intenrational Trade in the Procut Cycle. Journal of Eocnomics, 80, 190-207.

[6] Caves, R.E. (1971) International Corporations: The Industrial Economics of Foreign Investments. Economics, 38, 1-27.

[7] Knickerbocker, F.T. (1973) Oligopolistic Reaction and the Multinational Enterprise. Harvard University Press, Cambridge.

[8] Hymer, S. (1970) The Efficiency Contradictions of Multinational Corporations. The American Economic Review, 60, 441-448.

[9] Buckley, P.J. and Casson, M.C. (1976) The Future of the Multinational Enterprise. Homes and Meier Press, London.

[10] Dunning, J.H. (1980) Toward an Eclectic Theory of International Production: Some Empirical tests. Journal of International Business Studies, 11, 9-31. http://dx.doi.org/10.1002/tie.5060220301

[11] Sun, Q., Tong, W. and Yu, Q. (2002) Determinants of Foreign Direct Investment across China. Journal of International Money and Finance, 21, 79-113. http://dx.doi.org/10.1016/S0261-5606(01)00032-8

[12] Dunning, J.H. (2001) The Eclectic (OLI) Paradigm of International Production: Past, Present and Future. International Journal of the Economics of Business, 8, 173-190. http://dx.doi.org/10.1080/13571510110051441

[13] Dunning, J.H. (1993) Multinational Enterprises and the Global Economy. Addison Wesley, New York.

[14] Dunning, J.H. (1988) The Eclectic Paradigm of International Production: A Restatement and Some Possible Extensions. Journal of International Business Studies, 19, 1-31.

[15] Corrado, C. and Su, T. (1996) Skewness and Kurtosis in S \& P 500 Index Returns Implied by Option Prices. Journal of Financial Research, 19, 175-192.

[16] Dicken, P. (1992) Global Shift: The Internationalization of Economic Activity. Chapman Publishing, London.

[17] Park, H.M. (2011) Practical Guides to Panel Data Modeling: A Step-by-Step Analysis Using Stata. Tutorial Working Paper. International University of Japan, Minami Uonuma.

[18] Clark, T.S. and Linzer, D.A. (2012) Should I Use Fixed or Random Effects. Working Paper. Washington University, St Louis, No. 1315.

[19] O’Brien, R.M. (2007) A Caution Regarding Rules of Thumb for Variance Inflation Factors. Quality and Quantity, 41, 673-690. http://dx.doi.org/10.1007/s11135-006-9018-6

[20] Van Dijk, M.P. (2010) The Contribution of Cities to Economic Development, an Explanation Based on Chinese and Indian Cities. Lap, Saarbrucken, 61 p.

[21] CSP (2013) China Statistical Yearbook 2006. Beijing China Statistical Press, Beijing.

[22] Wheeler, D. and Mody, A. (1992) International Investment Location Decisions: The Case of US Firms. Journal of International Economics, 33, 75-76. 